\title{
Proceedings of the 4th Annual Meeting of the Alliance for Surgery and Anesthesia Presence (ASAP): Building Sustainable Surgical Systems
}

\author{
Stephen W. Bickler · Kelly McQueen
}

Published online: 17 April 2013

(C) Société Internationale de Chirurgie 2013

The Alliance for Surgery and Anesthesia Presence (ASAP) was founded in 2007 as a small working group of surgeons, anesthesiologists, public health professionals, and policy makers interested in a multidisciplinary approach to promoting strengthened infrastructure and expansion of capacity for delivery of surgical services in low income and middle income countries. The rapid growth of ASAP from its founding to the 4th Annual Meeting held in San Diego, November 9-11, 2011, was illustrated by the almost 300 delegates from over 20 countries in attendance. Hosted by the University of California, San Diego School of Medicine and Rady Children's Hospital, the three-day meeting included 75 oral presentation and 45 poster sessions.

One of the reasons for this high attendance was that ASAP members had the opportunity to participate in a World Health Organization Global Initiative for Emergency and Essential Surgical Care meeting that preceded the ASAP meeting. The San Diego WHO-GIEESC meeting was the first held in North America. The 5th WHOGIEESC meeting will be in Trinidad in October 14-15, 2013.

Stephen W. Bickler and Kelly McQueen contributed to the preparation of the manuscript and approved the final version.

Electronic supplementary material The online version of this article (doi:10.1007/s00268-013-2033-6) contains supplementary material, which is available to authorized users.

S. W. Bickler $(\square)$

Rady Children's Hospital, University of California, San Diego, 9500 Gillman Drive \#0739, La Jolla, CA 92093-0739, USA

e-mail: sbickler@ucsd.edu

K. McQueen

Harvard Humanitarian Initiative, 14 Story Street, 2nd Floor,

Cambridge, MA 02138, USA
The theme of the 4th ASAP meeting was Building Sustainable Surgical Systems. This subject was intended to draw attention to the fact that surgical care is not an independent enterprise but depends on a functioning health system. The meeting was organized into several sessions. The morning of the first day was designed as a surgical summit with presentations on the latest developments in global surgery. There were short presentations on the Burden of Surgical Disease (Dean Jamison), Cost Effectiveness of Surgical Care (Rich Gosselin), Economic Modeling of Surgical Disease (Scott Corlew), Surgical Systems (David Spiegel), Who Should Give Anesthesia? (Angela Enright), Surgical Programs at the World Health Organization (Meena Cherian), Clinical Officer Surgical Training in Africa (Eric Borgstein), Non-physician Surgeons in Mozambique (Mario Jacobs), Essential Surgical Skills (Ronald Lett), The Role of Surgical Sub-Specialities (Emmanuel Ameh), Implementing a Contextually Appropriate Surgical Training Program in Botswana (George Azzie), Consortium of Universities of Global Health (Haile Debas), Medical Education Partnership Initiative (Robert Schooley), and Faith-based Initiatives (John Tarpley). One of the more memorable moments of this session was Ron Lett's assertion that much of what we have been doing to improve surgical care in low income countries for the past 20 years has not worked, and we need to rethink our strategy.

The afternoon of the first day of the meeting was devoted to breakout sessions. The breakout session has been an important ASAP tradition as these small sessions allow delegates to identify research and work priorities for the coming year. The 2011 meeting breakout sessions covered a broad spectrum of topics: Metrics, Advocacy, Anesthesia Crisis, Nursing, Education and Training, Telemedicine, Quality Improvement, Academic Partnerships, Faith Based Initiatives, and Disaster Relief. 
The meeting also had several outstanding invited guest lectures. Emanuel Ameh from Ahmadu Bello University, Zaria, Nigeria, gave the keynote address at the opening dinner. His talk focused on the role of international partnerships for strengthening the health workforce in low income and middle income countries. At lunch the following day Jeremy Shiffman, a health policy expert from the American University in Washington, DC, discussed the principles underlying the rise and fall in interest in global health issues. On the third day of the meeting, Catherine deVries from the University of Utah described her vision of the future of global surgery.

As the ASAP meetings have grown, so have the side meetings. At the 2011 conference there were special sessions on the development and validation survey tools (David Chang) and on developing a global health career for medical students and other trainees (Georges Azzie and Donald Meier). The College of Surgeons of East and Central Africa hosted a side meeting to discuss potential collaborations. The main social event of the meeting was dinner at the Stephen Birch Aquarium, an excellent setting in which to continue the many discussions begun earlier in the conference.

New to the annual meeting were panel discussions that focused on clinical specialties: Anesthesia, Emergency Medicine, General Surgery, Neurosurgery, Nursing, Orthopedic Surgery, Pediatric Surgery, Plastic Surgery, Transplantation, and Trauma \& Burns. The meeting concluded with reports from breakout working groups and a wrap-up presentation that included a vision for the future.
The greatest disappointment to ASAP was our inability to attract corporate sponsorship for the ASAP and WHO meetings. A variety of explanations were offered by the nearly 30 surgical supply companies and pharmaceutical companies approached for sponsorship of these meetings. Clearly this is one area where advocacy and educational efforts need to be focused in the future. In addition to emphasizing the moral imperative driving support efforts to promote development of surgical care in disadvantaged populations, it may be worth pointing out that as surgical care develops in low income and middle income countries there will be new markets for surgical and anesthesia supplies. Developing a comprehensive strategy for garnering financial support from industry will be imperative as ASAP and WHO-GIEESC continue to grow.

In conclusion, the 4th Annual ASAP meeting was a great success, with its effects hopefully to be felt many years into the future. We are now looking forward to seeing reports from the 5th Annual ASAP Meeting, which was hosted by the Royal Australian College of Surgeons, Melbourne, Australia, September 27-28, 2012.

Acknowledgments The research was supported by Grant number R24TW008910 from the Fogarty International Center. The content is solely the responsibility of the authors and does not necessarily represent the official views of the Fogarty International Center or the National Institutes of Health. The NIH Common Fund supports the first award.

Conflict of interest The authors declare that they have no conflicts of interest. 